\title{
Jesse B. Jupiter: AO manual of fracture management: elbow and forearm
}

\author{
Thieme Verlag, New York, Stuttgart, 2009, 550 pp, 1540 figs, HardCover, \\ Euro (D) 269,95 CHF 448,00, ISBN: 978-3-13-149271-5
}

\author{
Vincent Travers
}

Received: 20 December 2010/Accepted: 21 December 2010/Published online: 28 January 2011

(c) Springer-Verlag 2011

Extremely complete book on all traumatology of the elbow and the two bones of forearm. Being based on classification of AO manual, the authors study for each type of fracture the various possibilities of osteosynthesis. After the first approaches are very well done (many very clear drawings and photographs, important bibliography), the authors explain with force operational photographs and drawings the principles of osteosyntheses on a caseby-case basis.
For the humerus, in addition to all the possible recent fractures, the pseudarthroses are also studied. Each time, a synopsis with the key points and the potential dangers is summarized at the end of the paragraph.

Deliver very precise and complete information, to put between all the hands of the traumatologists of the elbow. It is considered as regrettable that they did not specify the diagnosis and/or therapeutic potential place of the arthroscopy, even if this one is limited. 